\title{
A ESTRUTURA TEMÁTICA DE UM CONTO NA TRADUÇÃO DO JAPONÊS PARA O PORTUGUÊS: UM ENFOQUE SISTÊMICO-FUNCIONAL
}

\author{
Sonia Regina Longhi Ninomiya ${ }^{1}$ \\ Sumiko Nishitani Ikeda ${ }^{2}$
}

Resumo: A estrutura temática de uma oração é composta de Tema, o ponto de partida da mensagem, que dá proeminência a alguns elementos que a compõem, estabelecendo a base de interpretação para o restante da oração, o Rema. Pesquisadores mostram que a escolha do Tema gera implicações comunicativas em traduções literárias, interferindo na interpretação da mensagem. Buscando contribuir para o estudo dessa questão, este artigo compara um conto da literatura japonesa moderna e sua tradução para o português, para verificar a diferença na realização da estrutura temática nessas línguas, e a interferência dessa diferença na interpretação do conto. As análises, com o apoio da Linguística Sistêmico-Funcional, mostram que as diferenças na estruturação temática são motivadas por diferenças devidas à tipologia linguística, levando a diferenças de intepretação do texto.

Palavras-chave: tradução; estrutura temática; japonês; português; Linguística Sistêmico-Funcional.

Abstract: Thematic structure of a clause is composed of Theme, the starting point of the message that lends prominence to some elements that compose it, thus establishing the base to interpret the remainder of the clause, the Rheme. Researchers show that the choice of the Theme generate communicational implications in literary translation, interfering in the interpretation of the message. This thesis compares one short story taken from modern Japanese literature and its translation into Portuguese with the aim of analyzing the difference in the realization of the thematic structure in these languages, and the difference in the interpretation of the short story. The article is supported by the premises of Systemic-Functional Linguistics. The analyses show

1. Universidade Federal do Rio de Janeiro (UFRJ) sonianin@uol.com.br

2. Pontifícia Universidade Católica de São Paulo (PUCSP) sumiko@uol.com.br 
that differences in structure are driven by differences due to linguistic typology, and lead to differences in the text Interpretation.

Keywords: translation; thematic structure; Japanese; Portuguese; Systemic-Functional Linguistics.

\section{Introdução}

O tradutor é entendido como um sujeito inserido em um certo contexto cultural, ideológico, político e psicológico - fatores que não podem ser ignorados na elaboração de uma tradução, Segundo Slobin (1980), para a hipótese do determinismo linguístico, a língua é como é, tanto no léxico quanto na gramática, porque resulta primordialmente de necessidades existentes em uma cultura e do modo como essa cultura "enxerga" e recorta a realidade que a envolve, para então - essa é a hipótese - a língua tornar-se dona da situação, determinando um tipo específico de visão do mundo. Assim, continua Slobin, as línguas diferem muito tanto nas categorias que expressam como nos meios linguísticos que empregam para a expressão dessas categorias. Essas diferenças estão na base do fato conhecido de que a maioria das palavras não tem tradução perfeitamente equivalente de uma língua para outra.

Nesse contexto, lecionando a língua japonesa para falantes de português, havia um fato que resultava da diferença entre as tipologias das duas línguas: a dificuldade de manter a mesma ordem das palavras na tradução do japonês para o português, fazendo resultar ligeiras diferenças de interpretação da mensagem. O contato com as ideias da Escola de Praga sobre as noções de Tema ${ }^{3}$ e Rema, bem como com as propostas de Halliday (1994) sobre o assunto, mostrou-nos que poderia estar aí a explicação para a referida dificuldade.

Foi Mathesius (1939 apud FIRBAS 1974, p. 28), quem, influenciado pelas ideias de Weil (1844), estudou a questão de que o modo de expressão de um conteúdo pode interessar mais do que o próprio conteúdo. Para Weil, uma sentença possui um ponto de partida e uma meta no discurso. Mathesius propôs, então, a noção de Tema, definindo-o como "o ponto de partida do enunciado, aquilo que é conhecido ou pelo menos óbvio em uma dada situação", enquanto o Rema é "o núcleo do enunciado, aquilo que o falante afirma a respeito do Tema".

Com base na proposta de Mathesius, Halliday (1994), um dos principais idealizadores da Linguística Sistêmico-Funcional (LSF), assim se pronuncia: "Tema é o elemento que serve como ponto de partida da mensagem; é aquilo de que trata a oração" (1994, p. 37) . Como estrutura de mensagem, a oração consiste em um

3. Como para todas as outras funções será escrito com inicial maiúscula.

4. Gómez-González (2000) aponta como problemática essa conceituação de Tema, em que essas duas partes da sentença, em aposição, parecem confundir o critério sintático ("posição inicial") com o semântico ("aquilo de que trata"). 
Tema acompanhado de um Rema; e o que for escolhido como Tema será colocado em primeiro lugar na oração (HALLIDAY, 1994, p.37).

Os termos Tema e Rema, embora usados com frequência, ainda não foram definidos satisfatoriamente. Sobre a posição da LSF a respeito do Tema, Goutsos (1997) afirma que nem todas as propriedades do Tema, de Halliday, podem ser aceitas (FRIES; FRANCIS, 1992; HUDDLESTON, 1991 apud GOUTSOS, 1997), como acontece nas línguas em que os verbos aparecem, tanto quanto outros elementos, no começo de todos os tipos de oração, o que não acontece no inglês. Nesse contexto, o estudo de Gouveia e Barbara (2004) sobre Tema na língua portuguesa esclarece várias situações em que a escolha do Tema contraria as afirmações de Halliday.

A propósito, para Baker (1992, p. 172) - que ressalta a importância da estruturação temática na aceitabilidade e na naturalidade de um texto - os tradutores, em geral, não conhecem a importância dessa estrutura, fazendo mudanças aleatórias no posicionamento dos Temas sem se darem conta de que, assim, afetam a interpretação da mensagem proposta pelo texto original. Ventola (1995) já se referia às poucas pesquisas interessadas na estrutura temática e no padrão de progressão temática de um texto quando submetido ao processo tradutório.

Segundo Ninomiya (2012), alguns pesquisadores examinaram a tradução do ponto de vista da estruturação temática, mostrando que certas escolhas linguísticas para realizar o Tema geram implicações comunicativas (LIROLA; SMITH 2006; DUTRA; BISSACO 2005 apud NINOMIYA, 2012). Assim, Figueredo (2006), baseando-se na Linguística Sistêmico-Funcional examina estruturas da organização textual, enfocando suas estruturas temática e macrotemática (MARTIN; ROSE, 2003), buscando entender como autor e tradutor constroem a mensagem.

O objetivo deste artigo, com o apoio teórico-metodológico da Linguística Sistêmico-Funcional (HALLIDAY, 1994; HALLIDAY; MATTHIESSEN, 2004), é a comparação de um conto escrito em língua japonesa com a respectiva tradução em língua portuguesa, procurando buscar as implicações discursivas que eventuais mudanças temáticas, tendo em vista as tipologias que marcam as duas línguas, possam acarretar diferenças na interpretação entre as duas versões.

Este estudo deve responder às seguintes perguntas: (a) Que diferenças, na estrutura temática, resulta da tradução em português de um conto originalmente escritos em japonês? (b) Qual é a influência dessas diferenças na interpretação da mensagem no texto traduzido do japonês para o português? (c) O que determina essas diferenças?

Apresentamos as teorias que embasam nossa análise: a Linguística SistêmicoFuncional, com enfoque principalmente na estrutura temática e as opiniões diversas que cercam a noção de Tema; o Tema na língua japonesa e na portuguesa; a tipologia linguística; questões sobre o processo tradutório. 


\section{A Linguística Sistêmico-Funcional}

A Linguística Sistêmico-Funcional (LSF) (HALLIDAY, 1994; HALLIDAY; MATTHIESSEN, 2004) concebe a língua como sendo formada por muitos sistemas, cada um representando um tipo de escolha de sentido (geralmente inconsciente) feito pelos falantes (daí o nome 'sistêmico'); além disso, essas escolhas servem para os falantes realizarem coisas com a língua (daí o nome 'funcional').

Segundo Eggins (1994), que faz uma leitura da teoria hallidayana desde 1974, os sistemicistas, descrevendo o uso da língua em textos autênticos, examinam a sua estrutura em função desse uso. Os usuários da língua uns com outros, construindo três significados - ou metafunções: Ideacional (experiencial + lógico), Interpessoal e Textual) a fim de entender o mundo e o outro. A finalidade principal da língua é, portanto, semântica, para a LSF.

- Metafunção ideacional: refere-se ao conteúdo, assunto ou tópico de que as pessoas tratam.

- Metafunção interpessoal: refere-se às relações entre pessoas expressas na linguagem.

- Metafunção textual: refere-se à maneira como as pessoas organizam a fala e a escrita de acordo com seu propósito e as exigências do meio sócio-histórico-cultural.

Essas metafunções agem juntas: cada palavra que dizemos realiza as três metafunções. Em sendo assim, tudo que expressamos linguisticamente quer dizer, simultaneamente, três coisas: alguma coisa (ideacional) dita a alguém (interpessoal) de algum modo (textual).

\subsection{O Tema na LSF}

Segundo Halliday (1994), das várias estruturas que constroem uma oração, há uma que lhe dá o caráter de mensagem, conhecida como estrutura temática, com a atribuição de uma função especial a uma de suas partes, o Tema. Para Halliday e Matthiessen (2004), Tema é uma escolha significativa que especifica o ângulo a partir do qual o falante/escritor projeta sua mensagem: "É o que estabelece o cenário para a própria oração e a posiciona em relação ao texto que se desenrola". $\mathrm{O}$ autor propõe três tipos de Tema.

(a) IDEACIONAL (ou Topical) - O Tema coincide com: participante, processo ou circunstância (elementos da Transitividade).

(b) TEXTUAL - O Tema coincide com continuativo [sim, não, bem, oh, agora], estrutural [os temáticos obrigatórios: conjunções e relativos] e conjuntivos [adjuntos conjuntivos: isto é, além disso, do mesmo modo] 
(c) INTERPESSOAL - O Tema coincide com: vocativo, adjuntos modais [possivelmente, é claro, em minha opinião] e marcador de Modo [operador verbal Finito/um interrogativo QU-/imperativo let's, no caso do inglês].

OBS.: As minor clauses (frases sem verbo) não são analisados quanto a Tema, pois não possuem estrutura Temática (HALLIDAY, 1994).

Halliday (1994) distingue entre Tema não-marcado, quando coincide com o Sujeito da oração, e marcado nos demais casos. O Tema será múltiplo se for constituído de Tema topical (qualquer elemento da metafunção Ideacional, ou seja, Processo, Participante e Circunstância do sistema da Transitividade) antecedido por Tema interpessoal e/ou Tema textual. O Quadro 1 mostra casos de Tema múltiplo, em que ao Tema Topical, somam-se os Temas Interpessoal e/ou Textual.

As orações rankshifted (subordinada adjetiva restritiva) são incluídas no nome que qualificam. Assim, em: (1) $\underline{O \text { vaso }}$ que te dei foi caro, a oração "que te dei" é analisada juntamente com "o vaso". Mas Matthiessen (1995) não faz essa inclusão, considerando as rankshifted separadamente. Em nossa análise, adotamos a posição de Matthiessen, sublinhada em (1).

\section{Quadro 1 - Tema marcado e não-marcado}

\begin{tabular}{|c|c|c|c|}
\hline \multirow[t]{5}{*}{ Não-marcado } & & $\frac{\text { TEMA }}{\text { Não-marcado }}$ & $\underline{\text { REMA }}$ \\
\hline & & Maria & comprou um livro na faculdade. \\
\hline & & Comprou & um livro na faculdade \\
\hline & & O livro & foi comprado na faculdade. \\
\hline & & Na faculdade & Maria comprou o livro. \\
\hline & \multicolumn{2}{|c|}{ TEMA MÚLTIPLO } & \\
\hline & Marcado & Não-marcado & \\
\hline \multirow{4}{*}{ Marcado } & Felizmente & Maria & comprou o livro na faculdade. \\
\hline & Tema Interpessoal & Tema Topical & \\
\hline & Além disso & Maria & comprou o livro na faculdade. \\
\hline & Tema Textual & Tema Topical & \\
\hline
\end{tabular}

Nas orações complexas, quando a oração modificadora (subordinada adverbial) anteceder a principal, há duas possibilidades: (a) o Tema é a oração modificadora inteira; (b) o Tema é o Tema da oração modificadora. Assim em: (2) Se você conseguir o dinheiro irá a Portugal, o Tema tanto pode ser "se você conseguir o dinheiro", quanto "se você". Em nossa análise, adotamos a posição referida em (a), com toda a oração modificadora como Tema, como está em (2), sublinhada.

A sentença clivada, sublinhada em (3) Foi a Maria (quem rabiscou a parede), é o Tema predicado, segundo Halliday; já o Tema equativo, que aparece em sentença 
pseudo-clivada, do tipo, (4) O que o duque deu para minha tia (foi uma chaleira), está sublinhado em (4).

Uma complicação surge na análise de Tema em construções existenciais, tais como em:

(5) There is a problem. (para Halliday, there é o tema topical)

Nesse caso, autores como Leong Ping (2005), Fries (1995) e Vande Kopple (1991) consideram there + be bem como o participante existente como Tema, sublinhado em (5). Assim também se pronuncia Thomson (2004):

\begin{abstract}
O problema com o existencial "there" é que ele é sujeito ... e portanto deve ser o Tema, mas em termos experienciais ele não tem função representacional... e por isso não preenche o critério temático de expressar significado experiencial... Assim, parece fazer sentido incluir o processo no Tema, o que significa que o Tema inclui o conteúdo experiencial. (THOMPSON, 2004, p. 161)
\end{abstract}

Por outro lado, Goutsos (1997) observa que o modelo hallidayano de Tema não se aplica com tanto sucesso a línguas que têm uma ordenação de palavras bem menos rigorosa do que a do inglês (BAKER, 1992; BOWERS, 1988; GOUTSOS, 1992; HAKULINEN, 1989; RASHIDI, 1992 apud GOUTSOS, 1997). Se a estrutura Tema-Rema deve coincidir com o arranjo linear real da oração ("o que quer que seja escolhido como Tema será colocado em primeiro lugar na oração" (HALLIDAY, 1994, p.37), então os elementos verbais seriam sistematicamente Temas nas referidas línguas. Porém, como observa van Oosten (1984, p. 183 apud GOUTSOS, 1997), "É logicamente possível, mas praticamente inconcebível, que falantes de uma língua (as iniciadas por verbos) tenham consistentemente verbos como Temas oracionais e falantes de outras tenham consistentemente substantivos".

Porém, diz Goutsos, o modelo Tema-Rema, apesar de suas inadequações, pode oferecer intravisões inestimáveis sobre o papel de padrões sintáticos como sinais além da oração. A consideração da estrutura temática está relacionada a arranjos sintáticos que tiram vantagem das propriedades da linearidade da oração. A segmentação do discurso escrito expositivo não é acidental, e, sim, estruturada de tal forma que pode ser captada em termos de modelo dessa estrutura. A segmentação é, além disso, significativa: é uma das principais fontes de conectividade do texto e fornece ao escritor um mecanismo para a realização da coerência em um texto. 


\subsection{Tema na Língua Japonesa}

Em japonês, o Tema é salientado pela posposição do morfema $w a$ ao termo tematizado, segundo Teruya (2007, p. 111), podendo também, realizar-se sem essa sinalização; ou também por outros marcadores temáticos como, por exemplo: mo, koso, sae, dake, shika.

De forma geral, diz o autor, uma unidade de informação cria uma onda que se inicia com a informação Dada, e cresce culminando com a informação Nova, correspondendo à estrutura Tema/Rema, opinião que contraria a proposta de Halliday. Nota, por outro lado, que o Novo pode vir tanto no início quanto no fim da estrutura informacional. A propósito, as línguas, em geral, possuem estruturas que permitem colocar o Novo antes do Dado, como a cleft sentence (sentença clivada): "Foi a Mary que quebrou o vaso", em que "Foi a Mary" é informação Nova.

Já Thompson (1998, p. 234) conclui que wa não opera na estrutura temática (Tema/Rema), mas, sim, na estrutura informacional (Dado/Novo) da oração. Por outro lado, para Halliday $(1985,1994)$, há apenas um Tema topical na oração em inglês, com o que concorda Kuno (1973, p. 30-31), afirmando que, caso haja mais de um elemento salientado por $w a$ em uma oração, apenas o primeiro sintagma será o Tema; o segundo deve ser interpretado como Contrastivo.

\subsection{Tema na língua portuguesa}

O português, assim como o espanhol e o italiano, é considerado uma língua prodrop, ou seja, permite a elisão do sujeito e o posicionamento do Predicador (verbo principal, na LSF) em primeiro lugar na oração. Aparentemente a característica prodrop parece estar relacionada à rica morfologia verbal, em termos de pessoa e número. $\mathrm{O}$ fato de uma língua ser pro-drop, notam Gouveia e Barbara (2002; 2004a e b), acarreta algumas consequências: (a) não há pronomes expletivos como o inglês (it), por exemplo em: It is raining ou [It] Appeared a mouse in my office; (b) existe a possibilidade de posicionar o sujeito depois do verbo. Os autores, então, perguntam: Qual seria o Tema, em português, nos exemplos abaixo?

(6) Eu fui ao cinema ontem.

(7) Fui ao cinema ontem.

O problema é que estamos querendo analisar a língua portuguesa através de regras da língua inglesa, quando as duas línguas se comportam diferentemente. Gouveia e Bárbara (2002) mostram exemplos no português europeu para evidenciar que a explicitação ou não do Tema não implica diferença semântica, nem funcional, nessa língua.

O Tema, caso não seja realizado na oração, será inferido do cotexto ou da flexão verbal. Tudo isso faz sentido se se lembrar da definição de Tema como o Sujeito psicológico da oração: "that which is the concern of the message" (HALLIDAY, 1994, 
p. 37). É chamado psicológico porque é o que o falante tem em sua mente quando inicia a produção de uma oração (mesmo que não corresponda a nenhuma realização morfológica).

\section{A tipologia linguística}

Examinando uma extensa e variada amostra das línguas do mundo, Greenberg (1963 apud SLOBIN, 1980) e outros depois dele encontraram curiosas lacunas nas combinações possíveis dos traços gramaticais que constituem uma língua. Assim, uma língua que tem a ordem SVO (sujeito-verbo-objeto) - como o português - usa preposições. Outras - como o japonês - que têm a ordem SOV, usam posposições (sublinhadas no Quadro 3).

\begin{tabular}{|c|c|c|}
\hline \multicolumn{3}{|c|}{ Língua portuguesa } \\
\hline $\mathbf{S}$ & $\overline{\mathrm{V}}$ & $\mathbf{O}$ \\
\hline (eu) & Fui & à casa de Pedro \\
\hline \multicolumn{3}{|c|}{ Língua japonesa } \\
\hline $\mathbf{S}$ & $\mathbf{O}$ & $\underline{V}$ \\
\hline $\begin{array}{l}\text { watashi wa } \\
\text { [eu] }\end{array}$ & $\begin{array}{l}\text { Pedro no } \\
\text { [de Pedro] }\end{array}$ & $\begin{array}{l}\text { ikimashita } \\
\text { [fui] }\end{array}$ \\
\hline
\end{tabular}

Notemos, ainda, que o fato de serem língua espelhadas (VO-OV), isto é, apresentarem inversão entre verbo e objeto, acarreta inversão também na ordem do núcleo do sintagma nominal ("a casa") e seu adjunto adnominal ("de Pedro").

Por outro lado, o Quadro 4 nos mostra que a inversão VO-OV obriga a colocar próximos o verbo principal $(\mathrm{V})$ e o núcleo do objeto $(\mathrm{O})$ (sublinhados no Quadro 4).

\section{Quadro 4 - Estruturas sintáticas: japonesa e portuguesa}

\begin{tabular}{|c|c|c|}
\hline O exército & não pode capturar & o homem que era o líder da guerrilha. \\
\hline $\mathrm{S}$ & auxiliar $+\mathbf{V}$ & $\mathbf{O}+$ modificador \\
\hline \multicolumn{3}{|c|}{} \\
\hline Guntai $w a$ & guerira no riida no $\underline{\text { otoko } o}$ & $\underline{\text { taiho suru koto ga dekinakatta }}$ \\
\hline $\mathrm{S}$ & modificador $+\mathbf{O}$ & V+ auxiliar \\
\hline
\end{tabular}

Fonte: Slobin (1980) 
Assim, tanto na língua SVO como na língua SOV, para que VO (capturar, homem) ou OV (otoko [homem], taiho [capturar]) tenham seus elementos colocados juntos, os auxiliares do verbo e os modificadores do objeto são obrigados a se deslocarem para antes ou para depois desses elementos, sempre na direção oposta se consideradas essas línguas de diferentes tipologias. Essa seria, segundo Slobin (1980), uma restrição psicolinguística: a mente humana exige uma sintaxe - seja no português, seja no japonês - que expresse o fato da "captura do homem", colocando esses elementos em sequência, deixando os elementos secundários (auxiliar verbal ou modificador nominal) em posição que não atrapalhe essa sequência.

Por outro lado, segundo Slobin, deve-se considerar a variedade de classificações morfológicas obrigatórias incorporadas à gramática, às quais geralmente não se presta atenção. O Quadro 5 mostra um exemplo desse fato.

\section{Quadro 5 - A classificação morfológica}

\begin{tabular}{|c|c|c|c|c|}
\hline The & $\frac{\text { stone }}{\text { mineral }}$ & 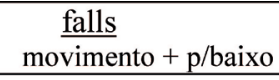 & 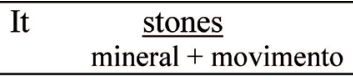 & $\frac{\text { down }}{\text { p/baixo }}$ \\
\hline $\begin{array}{l}\mathrm{He} \\
\text { mov }\end{array}$ & $\frac{\text { de }}{\text { cavalo }}$ & $\begin{array}{l}\text { out of the garden } \\
\text { p/for a }\end{array}$ & $\begin{array}{l}\text { El salió } \\
\text { mov }+ \text { p/for a }\end{array}$ & $\begin{array}{l}\text { ntando a caballo. } \\
\text { a cavalo }\end{array}$ \\
\hline
\end{tabular}

Em (5), a língua inglesa considera 'pedra' como um mineral estático e imóvel e, assim, trata-o como substantivo; já uma língua indígena nootka (distrito de British Columbia CAN), segundo Slobin, vê 'pedra' como um elemento dinâmico, dotado de movimento, e o trata como verbo. Por outro lado, 'fall' encerra em si dois lexemas: movimento + para baixo, que se unem ao mineral 'pedra'; já em 'stones', temos: movimento + mineral, ao que se precisa indicar 'down' (para baixo). E esse tipo de fenômeno linguístico acontece, diz Slobin, especialmente em línguas pertencentes a protolínguas diferentes, como entre português e japonês.

\section{Estudos de tradução}

Desde meados de 1960, as pesquisas sobre tradução não têm mais como foco o produto final da tradução e um olhar prescritivo sobre ele (BASSNET 1991; BAKER 1992; HICKEY 1998). O interesse volta-se para o processo tradutório, seus métodos e na inserção do texto na cultura da língua para a qual o texto é traduzido.

A tradução ganhou vigor como campo de estudo e pesquisa com a publicação How to do things with words, de Austin (1962). Embora Austin, na década de 1960, salientasse a relevância dos aspectos pragmáticos no tratamento da linguagem, a tradução ainda era 
percebida como simples transcodificação do léxico e da gramática. Essa percepção, segundo Baker (2001), emerge, principalmente, da postura de dois teóricos do assunto: Catford (1965) e Nida (1969), que entendiam a tradução como substituição do material textual de uma língua pelo material textual equivalente na outra língua. Arrojo (1986) relaciona essa visão à crença da existência possível de um texto original cujo significado fosse estável, clara e objetivamente transportável para outra língua.

Na década de 1980, segundo Snell-Hornby (1990), surge uma preocupação com a tradução como um processo transcultural, não mais abordada simplesmente como um fenômeno linguístico, mas como um fenômeno que vê a língua em uso em seu contexto social e cultural. Isso equivale à afirmação de Arrojo (1995, p. 3) de que "não existe nem tradução nem leitura que sejam neutras e que o tradutor é em certo sentido um coautor do texto que traduz", fato que estabelece uma intersecção com as teorias da linguagem que se preocupam com o uso funcional da língua.

A partir da década de noventa, muitos estudos sobre tradução adotam como parâmetro de análise a LSF preconizada por Halliday $(1985,1994)$ que concebe a língua como um sistema semântico cuja organização está ligada a funções de uso, relacionando a língua ao contexto social. Para Halliday, contexto e língua são interdependentes. A identificação das escolhas de significado depende da análise do contexto no qual se deu a escritura do texto, assim o texto é fruto de dois contextos sociais: (a) gênero (contexto cultural), (b) registro (contexto situacional) e o contexto ideológico, segundo o qual qualquer aspecto da estrutura linguística carrega significação ideológica.

A LSF tem contribuído significativamente para o desenvolvimento dos estudos da tradução. As três metafunções preconizadas por Halliday (1994) têm lançado interessantes intravisões para a abordagem da tradução, dentre os quais citamos os seguintes: Figueredo (2006), Pagano (2005), Paquilin (2005), Rodrigues (2005), Arús Hita (2004), Siqueira (2000), Naganuma (2000), Munday (1998), Vasconcellos (1992), Ventola (1995), Dourado; Gil; Vasconcellos (1995), Vasconcellos (1995), Baker (1992), Lucas (1991) e van Leuven-Zwart (1989, 1990), e que contribuíram para esclarecer algumas questões em nossas análises.

\section{Metodologia}

A pesquisa constitui-se em um estudo de caso, uma pesquisa cujos limites são esclarecidos em termos de resposta a perguntas feitas, de fontes de dados usadas, e do contexto envolvido (HOLLOWAY, 1997). A pesquisa tem o apoio da Linguística Sistêmico-Funcional, uma proposta teórico-metodológica de Halliday (1994), que possibilita relacionar as escolhas léxico-gramaticais do texto à estrutura da ideologia e das relações de poder do discurso. 


\subsection{Dados}

A pesquisa envolveu traduções para a língua portuguesa de três contos em língua japonesa, embora, para o presente artigo, apresentemos a análise de um conto apenas, Amagasa/ O guarda-chuva, por uma questão de espaço. Os contos foram selecionados tendo por princípio o fato de suas traduções terem sido feitas diretamente da língua japonesa por diferentes tradutores, notórios conhecedores de ambas as línguas, tendo tido ampla circulação no mercado editorial brasileiro. São eles:

\begin{tabular}{|l|l|}
\hline \multicolumn{1}{|c|}{ ORIGINAL } & \multicolumn{1}{c|}{ TRADUÇÃO } \\
\hline Amagasa, de Yasunari Kawabata (1932) & O guarda chuva (por Meiko Shimon) (2008). \\
Kami, de Yasunari Kawabata (1924) & O cabelo (por Meiko Shimon) (2008) \\
Butôkai, de Ryûnosuke Akutagawa (1919) & O Baile (por Madalena H. Cordaro e Junko Ota) (2008) \\
\hline
\end{tabular}

Halliday e Hasan (1989, p. 47) postulam que descrever o contexto de cultura e de situação contribui para "colher indícios sobre o pano de fundo cultural e as pressuposições que devem ser feitas" para que possamos produzir ou interpretar um texto conforme seus propósitos.

\subsubsection{Contexto de Cultura: o conto como gênero}

O conto como gênero literário foi identificado pela primeira vez nos Estados Unidos da América, por volta de 1880, e designado short story. O escritor e contista Cortázar (1974, p. 148) afirma que o conto é "um gênero de difícil definição, esquivo nos seus múltiplos e antagônicos aspectos" Para Poe (1842 apud GOTLIB, 2006, p. 34) a medida de extensão do conto é a narrativa "que requer de meia hora a uma ou duas horas de leitura atenta." Para Tchekhov (1966, apud GOTLIB, 2006, p.106), o conto é um gênero breve, forte, compacto e "deve causar impressão total no leitor" que "será mantido em suspense."

Ao considerarmos o conto uma narrativa curta, a questão da brevidade torna-se fundamental na sua construção. A fórmula para a brevidade, conclui Gotlib (2006, p. 35) é "conseguir, com o mínimo de meios, o máximo de efeitos". Além da brevidade, o conto é marcado pela intensidade, pela condensação da matéria para apresentar os seus melhores momentos, continua o autor. Aliada à intensidade, a tensão contribui para a caracterização do conto. A tensão respeito à técnica empregada pelo autor para desvendar aos poucos a narrativa, adiando a resolução da ação e assim, promove o sequestro do leitor, segundo Gotlib.

Os contos escolhidos são de escritores do séc. XIX, Kawabata (1899) e Akutagawa (1888). A época da escritura desses contos é uma época de grandes transformações sociais no Japão - a vitória na Primeira Grande Guerra, influências da Revolução Russa, a Democracia Taisho, movimentos sociais pelo voto universal e pela igualdade social - aliadas ao contato cultural e literário cada vez mais profícuo com o Ocidente. Esses autores refletem o gosto intelectualizado, a busca pelo ego do homem japonês moderno e o preciosismo da linguagem 
(SHINMA et al., 1982), em uma escrita reveladora da inquietação da época, como a de Akutagawa ou de refúgio na estética neossensorialista, como a de Kawabata.

\subsubsection{Contexto de Situação: campo, relação e modo nos contos analisados}

A caracterização do contexto situacional, ou Registro, por meio da análise de Campo, Relações e Modo, torna menos subjetivas as avaliações (GOATLY, 1997). Assim, Amagasa/O guarda-chuva é um conto (Modo), que se refere a um jovem casal e um fotógrafo (Relações), tratando do seguinte assunto (Campo): o casal procura um fotógrafo em dia chuvoso. Diante da timidez de ambos, o fotografo sugere que posem como se fossem um casal, e a sensação daí advinda marca-os para sempre. Na volta, a menina é quem leva o guarda-chuva, demonstrando ao garoto o sentimento de lhe pertencer.

\subsection{Procedimentos analíticos}

Devemos esclarecer que a análise contrastiva da estruturação temática não trata do Rema, mas, por vezes, as considerações semânticas sobre o Tema levam-nos a considerar o Rema. A análise segue os seguintes passos, tendo em vista a proposta de Halliday (1994):

(i) apresentação em paralelo do conto na íntegra e sua tradução, divididos em trechos de acordo com o assunto tratado;

(ii) seleção das diferenças temáticas entre as duas versões, segundo o Quadro 1, observando o seguinte:

(a) não incluir as orações adjetivas restritivas (rankshifted) no nome que qualificam;

(b) será Tema a oração subordinada que anteceder a principal;

(c) considerar o Tema predicado (e.g. Foi a Maria (quem fez isso);

(d) considerar o Tema equativo (e.g. O que o duque deu para minha tia (foi ...);

(e) considerar "haver" + o Existente (e.g. Há livros sobre a mesa.) (PING, 2005).

(iii) discussão dos resultados após cada trecho analisado;

(iv) discussão Geral após a análise do texto na íntegra.

PS: Os Temas, quando idênticos nas duas línguas, não serão analisados. 


\title{
5. Análise de dados
}

\begin{tabular}{c|c|c|}
\multirow{2}{*}{ Codificação } & $\neq$ & Temas diferentes \\
\cline { 2 - 4 } & $=$ & Temas iguais \\
\hline
\end{tabular}

OBS.: Tradução: entre colchetes

\begin{tabular}{|c|c|}
\hline$A M A G A S A$ & O GUARDA-CHUVA \\
\hline \multicolumn{2}{|c|}{ PRIMEIRO TRECHO } \\
\hline $\begin{array}{l}\text { (1) Nure wa shinai ga, nanto wa nashi ni hada } \\
\text { Tema Ideacional: Ator [(A chuva) Molhar (não } \\
\text { molhava)] } \\
\text { no shimeru, tsuyu no yôna harusame lata. }\end{array}$ & \begin{tabular}{l|l}
$\neq$ & Era uma chuva fina de primavera como \\
uma \\
Tema Ideacional: Existente) \\
\\
névoa que não molhava, mas dava a sensação \\
de umedecer a pele.
\end{tabular} \\
\hline $\begin{array}{l}\text { (2) Omote ni kakedashita shôjo wa, shônen } \\
\text { no } \\
\text { [(foi) para fora]Tema Ideacional: Circunstância } \\
\text { kasa o mite hajimete, }\end{array}$ & \begin{tabular}{l|l}
$\neq$ & $\begin{array}{l}\text { A jovem que saíra correndo de casa, só se deu } \\
\text { Tema Ideacional: Experienciador }\end{array}$ \\
conta disso ao ver o guarda-chuva do rapaz.
\end{tabular} \\
\hline "Ara. Ame na no ne." & $=-$ Oh! Está chovendo? \\
\hline \multicolumn{2}{|l|}{ OBS.: O Tema idêntico não será levado em conta. } \\
\hline \multicolumn{2}{|c|}{ Tema diferentes } \\
\hline $\begin{array}{l}\text { (1) (A chuva) Não molhar (Ideac: Ator) } \\
\text { (2) (Foi) Para fora (Ideac: Circunst) }\end{array}$ & $\begin{array}{l}\text { Chuva fina de primavera Ideac: Existente) } \\
\text { A jovem (não se deu conta) (Ideacional: } \\
\text { Experienciador) }\end{array}$ \\
\hline
\end{tabular}

Interpretação da análise: $\mathrm{O}$ trecho - que traz o contexto situacional - apresenta 2 Temas diferentes: Em (1), enquanto Amagasa (A) fala da "chuva que não chegava a molhar"; O Guarda-chuva $(\mathrm{G})$ refere-se à "chuva fina de primavera".

A diferença em (1) resulta da diferença entre as tipologias das duas línguas: não há no japonês a oração adjetiva - sublinhada a seguir -, no caso, "(chuva) [...] que não molhava", mas esse significado antecipa-se ao nome modificado "tsuyu" (líquido =chuva):

\author{
nure wa shinai ga $[\ldots]$ tsuyu \\ molhar não molhava chuva
}


O mesmo acontece na diferença de Temas em (2):

$$
\begin{array}{cr}
\text { Omote ni } & \begin{array}{r}
\text { kakedashita } \\
\text { para fora }
\end{array} \quad \begin{array}{r}
\text { shojo wa, } \\
\text { correu }
\end{array}
\end{array}
$$

ou seja, o modificador é preposto ao núcleo no japonês, enquanto é posposto em português. Como vimos na teoria, o fato decorre das diferentes tipologias: SOV para o japonês e SVO para o português. Daí, a inevitável diferença entre os Temas.

\section{SEGUNDO TRECHO}

(1) Shônen wa ame no tame yori mo, shôjo ga [O rapaz mais do que pela chuva, mas pela timidez] Tema Ideacional: Experienciador

suwatteiru mise saki o tôru hazukashisa o kakusu tameni, hiraita kasa datta.

\section{$\neq \underline{\text { Não foi }}$ propriamente por causa da} chuva,

Tema múltiplo (Interp+Ideac: Existente)

mas o rapaz abrira o guarda-chuva para disfarçar sua timidez, ao passar em frente à lojinha onde a jovem estava sentada.

\section{(2) Shikashi, shônen wa damatte shôjo no} [No entanto, o rapaz (sem dizer)] Tema Múltiplo (Textual + Ideacional: Verbal)

karada ni kasa o sashikakete yatta.

(3) Shôjo wa kata ippô no kata dake o kasa ni A jovem (pôs apenas um ombro sob o guarda-chuva) Tema Ideacional: Ator (lexical) ireta. $\neq \quad$ No entanto, sem dizer nada, ele estendeu o Tema múltiplo (Textual + Interp + Ideac: Verbal) guarda-chuva para cobri-la.
(4) Shônen wa nurenagara ohairi to, shôjo ni [O rapaz, embora molhando-se, não conseguia aproximar-se] Tema Ideacional: Ator)

mi o yoseru koto ga dekinakatta.
\# $\quad$ Ela apenas deixou um ombro ser coberto pelo Tema Ideacional: Ator (pronome) guarda-chuva.
(5) Shôjo wa jibun mo kata te o kasa no e ni [A jovem pensava que ...] Tema Ideacional: Experienciador

mochisoe tai to omoi nagara, shikamo kasa no naka kara nigedashi sô ni bakari shite ita.
Molhado, o rapaz não conseguia aproximarse

Tema (Ideacional:Circunstância) [Mesmo molhado]

e convidá-la a se proteger.

$\neq$ Ela queria segurar com ele o cabo e, no entanto,

Tema Ideacional: Ator

o tempo todo parecia estar prestes a fugir do guarda-chuva.

\section{Tema diferentes}

(1) O rapaz (Ideac: Exper)

(2) No entanto, o rapaz (sem dizer) (Múlt: Text.+Ideac: Verbal)

(3) A jovem (Ideac: Ator - lexical)

(4) O rapaz (não conseguia aproximar-se) (Ideac:

Ator )

(5) A jovem (Ideac: Experienciador - lexical)
Não foi ... a chuva (Múltiplo: Interp + Ideac:Exist) No entanto, sem dizer (Múltiplo: Text+Ideac:

Verbal)

Ela (deixou) (Ideac: Ator - pronome)

Molhado (Ideac: Circunst)

Ela (Ideac: Ator - pronome) 
Interpretação da análise: Notemos em (1) o Tema é "shonen" (o rapaz) com Experienciador da timidez, enquanto em português o foco incide na "chuva", participante Existencial.

Em (2), o japonês obriga a explicitar o sujeito "shonen" enquanto que em português é possível recuperar - pelo contexto - o sujeito de "dizer", embora indicado pelo morfema zero do infinitivo. É, também, consequência da diferença entre as tipologias das duas línguas.

Em (3) e em (5), notemos, no japonês, pelo Tema lexical "shojo" (a jovem), enquanto o português usa o pronome ("ela"). Há no japonês o grupo nominal "ka no jo" (a tal jovem), que, entretanto, não equivale exatamente ao pronome português.

Em (4), tal como em (1) deste trecho, o japonês apresenta o Tema "shonen", enquanto o português recorre a um adjunto adverbial (embora) "molhado".

Em resumo, enquanto o texto japonês apresenta a situação emocional (Experienciadores de Processo Mental) que envolve shonen X shojo, o texto em português está mais preocupado em apresentar as circunstâncias (3) que cercam esse envolvimento. 


\section{TERCEIRO TRECHO}

\begin{tabular}{|c|c|c|}
\hline Futari wa shashin' ya e haitta. & $=$ & Os dois entraram no estúdio fotográfico. \\
\hline $\begin{array}{l}\text { Shônen no chichi no kanshi ga tôku ten'nin } \\
\text { suru. Wakare no shashin data. }\end{array}$ & $=$ & $\begin{array}{l}\text { O pai do rapaz, um funcionário do governo, } \\
\text { fora transferido para uma terra distante. Era a } \\
\text { fotografia de despedida. }\end{array}$ \\
\hline $\begin{array}{l}\text { Dôzo ofutari de koko e o narabi ni natte to, } \\
\text { shashin wa nagaisu o sashita ga, shônen wa } \\
\text { shôjo to narande suwaru koto da dekinakatta. }\end{array}$ & $=$ & $\begin{array}{l}\text { Por favor, (ambos) sentem juntos aqui. O } \\
\text { fotografo indicou o sofá, mas eles não } \\
\text { conseguiram sentar lado a lado. }\end{array}$ \\
\hline $\begin{array}{l}\text { Shônen wa shôjo no ushiro ni tatte, futari no } \\
\text { karada ga dokoka de musubareteiru to omoi } \\
\text { tai tame ni, isu o nigitta yubi o karuku shôjo } \\
\text { no haori ni furesaseta. Shôjo no karada ni } \\
\text { fureta hajime datta. }\end{array}$ & $=$ & $\begin{array}{l}\text { O rapaz se pôs de pé atrás da jovem e, desejoso } \\
\text { de sentir seu corpo ligado ao dela em algum } \\
\text { ponto, encostou de leve os dedos, que } \\
\text { seguravam o respaldo da cadeira, no casaco do } \\
\text { quimono da jovem. Era a primeira vez que } \\
\text { tocava no corpo dela. }\end{array}$ \\
\hline $\begin{array}{l}\text { Sono vubi ni tsutawaru honoka na taion de, } \\
\text { [Nesse dedo (que transmitia o calor)] } \\
\text { Tema Ideacional: Circunst. } \\
\text { shônen wa shôjo o hadaka de dakishimeta yô } \\
\text { na atatakasa o kanjita. }\end{array}$ & $\neq$ & $\begin{array}{l}\text { Por causa do tênue calor que subia pelos } \\
\text { dedos, Tema Ideacional: Circunst + oração adjetiva) } \\
\text { ele sentiu um calor agradável, como se a } \\
\text { apertasse nua em seus braços. }\end{array}$ \\
\hline $\begin{array}{l}\text { Issho kono shashin o miru tabi ni, shôjo no } \\
\text { taion o omoidasu darô. }\end{array}$ & $=$ & $\begin{array}{l}\text { Por toda sua vida, ele se recordaria desse calor } \\
\text { sempre que olhasse aquela fotografia. }\end{array}$ \\
\hline \multicolumn{3}{|c|}{ Tema diferentes } \\
\hline Nesse dedo (Ideac: Circunst.) & & $\begin{array}{r}\text { Por causa [...] dedos (Ideacional: Circunst }+ \text { oração } \\
\text { adjetiva) }\end{array}$ \\
\hline
\end{tabular}

Interpretação da análise:

"sono yubi ni tsutawaru honoka na taion de X "por causa do tênue calor que subia pelos dedos"

nesse dedo transmitia tênue calor tênue calor subia pelos dedos

As línguas espelhadas, VO-OV, como é o caso do português/japonês, apresentam respectivamente "preposição" e "posposição". A posposição "ni" do japonês equivale à preposição "em", português; a posposição "de" indica causa como o "por causa" do português.

Por outro lado, o português conta com uma oração subordinada adjetiva, enquanto que esse tipo de construção inexiste no japonês. Além disso,

o português pospõe o modificador de "calor" ("que subia pelos dedos"), o japonês antepõe a subida ("tsutawaru") ao "taion" (calor). 


\begin{tabular}{|c|c|c|}
\hline \multicolumn{3}{|c|}{ QUARTO TRECHO } \\
\hline $\begin{array}{l}\text { "Mô ichimai ikaga deshô." } \\
\text { [Mais uma (folheável = foto)] Tema Ideacional: Meta. }\end{array}$ & $\neq$ & $\begin{array}{l}\text { - (Vocês) Gostariam de tirar mais uma foto? } \\
\text { Tema Ideacional: Meta: de "tirar") }\end{array}$ \\
\hline $\begin{array}{l}\text { Ofutari de o narabi ni natta tokoro o, } \\
\text { jôhanshin o ôkiku" }\end{array}$ & $=$ & $\begin{array}{l}\text { Os dois lado a lado, da cintura para cima, bem } \\
\text { de perto... }\end{array}$ \\
\hline $\begin{array}{l}\text { Shônen wa tada unazuite, "kami wa?" to, } \\
\text { shôjo ni kogoe de itta. }\end{array}$ & $=$ & $\begin{array}{l}\text { O rapaz apenas fez que sim. } \\
\text { - E o cabelo? -perguntou baixinho à menina. }\end{array}$ \\
\hline $\begin{array}{l}\text { Shôjo wa, hyoi to shônen o miagete hô o } \\
\text { Tema Ideacional (Participante) } \\
\text { someru to, akarui yorokobi ni me o } \\
\text { kagayasete, kodomono yô ni, sunao ni } \\
\text { batabata to keshôshitsu e hashitte itta. }\end{array}$ & $\neq$ & $\begin{array}{l}\text { Por um instante, ela ergueu o olhar para ele, } \\
\text { Tema Ideacional (Circunstância) } \\
\text { corando um pouco; então, com os olhos } \\
\text { brilhando de felicidade como uma criança, } \\
\text { correu docilmente para o toucador em passos } \\
\text { leves. }\end{array}$ \\
\hline \multicolumn{3}{|c|}{ Tema diferentes } \\
\hline $\begin{array}{l}\text { (1) Mais uma (foto) (Ideac: Meta ["foto"] } \\
\text { (2) A jovem (Ideac: Experienciador) }\end{array}$ & & $\begin{array}{l}\text { Vocês) (Ideac: Meta [de "tirar"] } \\
\text { Por um instante (Ideac: Circunst) }\end{array}$ \\
\hline
\end{tabular}

Interpretação da análise: Para a língua japonesa, a expressão da unidade ("um", "uma", no português, ou seja: unidade + masculino ou unidade +feminino) inclui necessariamente outros itens lexicais: "hitori" (unidade + pessoa), "ippiki" (unidade + animal), "issatsu" (unidade + livro), "ikko" (unidade + pequeno), "ippon" (um + longo), "itto" (unidade + grande) e assim por diante.

(1) No caso de "ichimai" (unidade + folheável), o fotógrafo refere-se à fotografia, sem precisar mencioná-lo, já que o item pode ser recuperado pelo contexto. "Mô ichimai" colocaria foto como Tema: "mais uma foto", como foi traduzido em português. O Tema em português é "vocês" (também omitido, graças à morfologia de flexão verbal - "m" - em "gostariam").

(2) A diferença de Tema - "shojo" (a jovem) X "por um instante", parece demonstrar uma tendência nesta tradução em português para a preferência pela Circunstância. Esse fato já ocorre no trecho 2 ("molhado", "não foi ... por causa..."), bem como no trecho 3 ("por causa do tênue calor".

Novamente, questões de diferença tipológica influem na seleção do Tema. 


\begin{tabular}{|c|c|}
\hline \multicolumn{2}{|c|}{ QUINTO TRECHO } \\
\hline 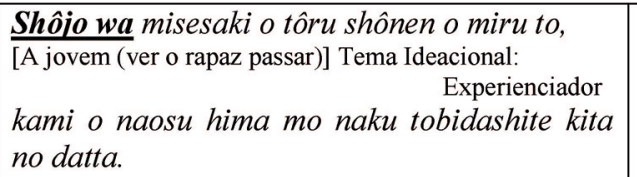 & \begin{tabular}{l|l}
$\neq$ & Quando vira o rapaz passar na frente da \\
lojinha, Tema oracional \\
ela saíra voando, sem ter tempo de ajeitar o \\
cabelo.
\end{tabular} \\
\hline $\begin{array}{l}\text { Kaisuibô o nuida bakari no yô ni midareta } \\
\text { kami ga, shôjo wa taezu ki ni natte ita. }\end{array}$ & $=\mid \begin{array}{l}\text { Como se acabasse de tirar a touca de banho de } \\
\begin{array}{l}\text { mar, seus cabelos estavam em desalinho, } \\
\text { deixando-a ansiosa. }\end{array}\end{array}$ \\
\hline $\begin{array}{l}\text { Shikashi, otoko no mae de wa hazukashikute, } \\
\text { okurege o kakiageru keshô no mane mo } \\
\text { dekinai shôjo datta. }\end{array}$ & $=\mid \begin{array}{l}\text { No entanto, na frente dele, ela era uma menina } \\
\text { inibida que não conseguia arriscar um gesto } \\
\text { para ajeitar os fios rebeldes de seus cabelos. }\end{array}$ \\
\hline $\begin{array}{l}\text { Shônen wa mata kami o naose to iu koto wa } \\
\text { shôjo o hazukashimeru to omotte ita no data. }\end{array}$ & \begin{tabular}{l|l}
$=$ & $\mathrm{O}$ rapaz, por sua vez, temia que pudesse \\
ofendê-la se lhe pedisse para ajeitá-los.
\end{tabular} \\
\hline $\begin{array}{l}\text { Keshôshitsu e iku_shôjo no akarusa wa, } \\
\text { shônen } \\
\text { [Para o toucador (dirigir-se)] Tema Ideacional: } \\
\text { o mo akaruku shita. }\end{array}$ & \begin{tabular}{l|l}
$\neq$ & $\begin{array}{l}\text { A alegria da jovem ao se dirigir ao toucador } \\
\text { Tema Ideacional (Participante) }\end{array}$ \\
alegrou-o também.
\end{tabular} \\
\hline $\begin{array}{l}\text { Sono akarusa no ato de, futari wa atarimae no } \\
\text { koto no yô ni, mi o yosete nagaisu ni suwatta. }\end{array}$ & $=\begin{array}{l}=\text { Depois de sentirem essa alegria, os dois } \\
\begin{array}{l}\text { sentaram-se juntos no sofá com toda } \\
\text { naturalidade. }\end{array}\end{array}$ \\
\hline \multicolumn{2}{|c|}{ Tema diferentes } \\
\hline $\begin{array}{l}\text { (1) A jovem (Ideac: Exper) } \\
\text { (2) Ao toucador (Ideac: Circunst) }\end{array}$ & $\begin{array}{l}\text { Quando vira o rapaz passar na frente da lojinha } \\
\text { (Circunstância oracional) } \\
\text { A alegria da jovem (Ideac: Fenômeno) }\end{array}$ \\
\hline
\end{tabular}

Interpretação da análise:

(1) Em: "Shôjo wa misesaki o tôru shônen o miru to,"

A jovem defronte à loja passar o rapaz ver

seria possível dizer "misesaki o tôru shônem o miru to, shojo wa", mas a primeira versão foi preferida, ao que faz crer, devido à progressão temática (veja o período anterior, com o Tema "shojo wa").

O tema do texto japonês é "shojo", a jovem, enquanto que o texto português elege uma Circunstância. Assim o texto japonês enfoca o comportamento da jovem, sua timidez, sua delicadeza, referindo-se, por exemplo, exclusivamente à sua alegria ("akarusa") e não como o texto em português que envolve o rapaz também. 


\begin{tabular}{|c|c|}
\hline \multicolumn{2}{|c|}{ SEXTO TRECHO } \\
\hline $\begin{array}{l}\text { Shashin'ya o de yô to shite, shônen wa } \\
\text { amagasa o sagashita. }\end{array}$ & \begin{tabular}{l|l}
$=$ & Quando ia saindo do estúdio fotográfico, \\
rapaz procurou seu guarda-chuva.
\end{tabular} \\
\hline $\begin{array}{l}\text { Futo miru to saki ni deta shôjo ga sono kasa o } \\
\text { [Ao olhar para] Tema múltiplo (Text + Ideac: } \\
\text { Experienciador) }\end{array}$ & \begin{tabular}{l|l}
$\neq$ & $\begin{array}{l}\mathbf{E}, \text { viu que a jovem, que saíra antes dele, o } \\
\text { Tema múltiplo (Text + Ideac) }\end{array}$ \\
$\begin{array}{l}\text { aguardava na frente do estúdio com o guarda- } \\
\text { chuva dele. }\end{array}$
\end{tabular} \\
\hline $\begin{array}{l}\text { Shônen ni mirarete hajimete, shôjo wa jibun } \\
\text { [(Sendo olhada) pelo rapaz] Tema Ideacional: Ator } \\
\text { ga shônen no kasa o motte deta koto ni ki ga } \\
\text { tsuita. }\end{array}$ & \begin{tabular}{l|l} 
Só quando sentiu o olhar do rapaz, ela se \\
deu \\
Tema múltiplo (Interp + oracional) \\
conta de que estava com o guarda-chuva dele.
\end{tabular} \\
\hline $\begin{array}{l}\text { Soshite, shôjo wa odoroita. } \\
\text { [Então, a jovem] }\end{array}$ & \begin{tabular}{l|l}
$\neq$ & (Ela) Ficou surpresa.
\end{tabular} \\
\hline \multicolumn{2}{|c|}{ Tema diferentes } \\
\hline $\begin{array}{r}\text { (1) Ao olhar de relance (Múltiplo: Text + Ideac: } \\
\text { Exper) } \\
\text { (2) O rapaz (Ideac: Ator } \\
\text { (3) Então, a jovem (Múltiplo: Text + Ideac: Exper) }\end{array}$ & $\begin{array}{l}\text { E viu (Múltiplo: Text + Ideac) } \\
\text { Só quando sentiu o olhar do rapaz (Múltiplo: Inter } \\
+ \text { oracional) } \\
\text { Ela (Tema Ideac: Experienc) }\end{array}$ \\
\hline
\end{tabular}

Interpretação da análise: O Tema em (1) envolve uma Circunstância ("futo") (de relance) que concorre para a descrição do casal (no caso, do rapaz) como tímidos e inexperientes na questão do relacionamento amoroso.

Em (2), novamente a tendência do texto em português para a Circunstância, em vez de eleger "shonen", como é feito no japonês para estabelecer a progressão temática, enfocando a relação entre os jovens.

(3) mostra a tendência ao pronome em lugar da anáfora lexical. 


\begin{tabular}{|c|c|}
\hline \multicolumn{2}{|c|}{ SÉTIMO TRECHO } \\
\hline $\begin{array}{l}\text { Nani gokoro nai shigusa no uchi ni, kanojo } \\
\text { ga } \\
\text { Tema Ideacional: Circunstância) } \\
\text { kare no mono da to kanjite iru koto o } \\
\text { arawashita de wa nai ka.] }\end{array}$ & \begin{tabular}{l|l}
$=$ & $\begin{array}{l}\text { Com um gesto tão involuntário, } \\
\text { Tema Ideacional (Circunstância) }\end{array}$ \\
revelou os sentimentos de que pertencia a ele.
\end{tabular} \\
\hline $\begin{array}{l}\text { Shônen wa kasa o motô to ienakatta. Shôjo wa } \\
\text { kasa o shônen ni tewatasu koto ga } \\
\text { dekinakatta. }\end{array}$ & 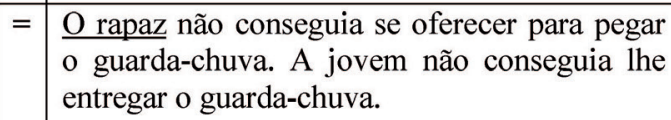 \\
\hline $\begin{array}{l}\text { Keredomo shashin'ya e kuru michi to wa } \\
\text { [Porém, (a vinda a) o fotógrafo] Tema múltiplo (Text + } \\
\text { Ideac: Circunt) } \\
\text { chigatte, futari wa kyû ni otona ni nari, fûfu no } \\
\text { yô na kimochi de kaette iku no data. }\end{array}$ & \begin{tabular}{l|l}
$\neq$ & Contudo, (algo) foi diferente do que fora no \\
Tema múltiplo (Text + Ideac) & $\begin{array}{l}\text { caminho de ida para o estúdio fotográfico. De } \\
\text { repente, eles se tornaram adultos e retornaram } \\
\text { para suas casas sentindo-se marido e mulher. }\end{array}$
\end{tabular} \\
\hline $\begin{array}{l}\text { Kasa ni tsuite no tada kore dake no koto de. } \\
\text { Tema Ideacional }\end{array}$ & \begin{tabular}{l|l}
$\neq$ & $\begin{array}{l}\text { Por causa desse pequeno episódio do } \\
\text { guarda-chuva, } \\
\text { Tema Ideacional por isso. }\end{array}$
\end{tabular} \\
\hline \multicolumn{2}{|c|}{ Temas diferentes } \\
\hline $\begin{array}{r}\text { (1) Porém, (a vinda a) o fotógrafo (Múltilplo: Text } \\
+ \text { Ideac) } \\
\text { (2) (Referente a) o guarda-chuva (Tema Ideac: } \\
\text { Circunst) }\end{array}$ & $\begin{array}{l}\text { tontudo, (algo) foi diferente (Múltiplo: Text }+ \\
\text { Ideac) } \\
\text { Por causa desse pequeno episódio do guarda- } \\
\text { chuva (Ideac: Circunstância) }\end{array}$ \\
\hline
\end{tabular}

Interpretação da análise: As escolhas temáticas recaem - agora - para os motivos que, finalmente, aproximam fisicamente os tímidos jovens: a chuva e o guardachuva - que recapitula o contexto situacional do início do conto, além do fotógrafo que os fez sentarem-se próximos um do outro.

\section{DISCUSSÃO GERAL DOS RESULTADOS}

A análise mostra que o conto apresenta 15 Temas iguais e 17 diferentes. As escolhas temáticas refletem, na maioria dos casos, a diferença de tipologia que envolve as duas línguas. O fato de serem línguas espelhadas VO-OV, traz como consequência uma séria de inversões, influindo inevitavelmente na ordem dos constituintes, o que desvia a atenção e consequente interpretação do leitor. 
Por outro lado, enquanto o texto em japonês enfoca a relação entre os dois jovens - com a maioria dos Temas recaindo em "shojo" (a jovem) ou "shonen" (o jovem), a tradução prefere a Circunstância como escolha temática, com isso deixando de mostrar a relação amorosa delicada e extremamente discreta que começa a brotar entre eles.

Note-se também o uso frequente da anáfora pronominal para referência aos jovens ("ela", "ele"), enquanto que - porque não é comum no uso da língua - o japonês dá preferência à anáfora lexical ("shonen", "shojo").

O que se perde, nessa tradução é o esquema geral do conto, que se inicia-se com uma situação - a chuva - que futuramente terá consequências na vida de dois jovens; a descrição de dois jovens inexperientes na relação amorosa, sua delicadeza e timidez no trato com o outro; a necessidade da intervenção da natureza, com consequente recurso do guarda-chuva - e a intervenção de um ser humano - o fotógrafo - que precisam intervir para aproximar os dois jovens.

Assim sendo, esse esquema de gênero deveria ser respeitado na tradução. As Circunstâncias, frequentes nos Temas do texto em português, acabam tirando do foco as incertezas, o desejo, a preocupação que dizem respeito ao jovem casal, e que, assim, deveriam ser os Temas da maioria dos estágios desse conto.

Com isso, esperamos ter contribuído, com o auxílio de teorias de diversas origens, para uma questão central da tradução: o respeito ao Tema do original, o sujeito psicológico, em termos da Linguística Sistêmico-Funcional, que influi decisivamente na interpretação de um uma mensagem.

\section{Referências Bibliográficas}

ARÚSHITA, J. English and Spanish structures: the textual metafunction as a contrastive tool for the analysis of languages. In: BANKS, D. (Ed.) Text and Texture: Systemic-Functional viewpoints on the nature and structure of text. Paris: L'Harmattan, 2004, p.173-190.

ARROJO, R. Oficina de Tradução - A Teoria na Prática. São Paulo: Ática, 1986.

AUSTIN, J. L. How to do things with words. New York: Oxford University Press, 1962.

BAKER, M. In other words: a course on translation. London: Routledge, 1992.

. (Ed.). Routledge Encyclopedia of Translation Studies. London \& New York: Routledge, 2001.

BASSNETT, S. Translation Studies. London \& New York: Routledge, 1991.

CATFORD, J.C. A Linguistic Theory of Translation. London, Oxford University Press, 1965.

CORTÁZAR, J. Valise de Cronópio. Tradução de Davi Arrigucci Júnior. São Paulo, Perspectiva, 1974, p. 148.

DOURADO, M. R.; GIL, G.; VASCONCELLOS, M. L. Contribuitions of Systemic linguistics to tranlation studies. In: Anais do XIII Encontro Nacionalk de Professores Universitários de Lingua Inglesa - Enpuli. Rio de Janeiro: Edtora da PUC, 1995, p. 200-240. 
EGGINS, S. An introduction to systemic functional linguistics. Londres: Pinter, 1994.

FIGUEREDO, G. P. The flow of information in "Brian Aldiss Supertoys Last All Summer Long" and its translation into brazilian portuguese. 2006. Disponível em: <http:// www.pucsp.br/isfc/proceedings/Artigos>. Acesso em: 17 jul. 2009.

FIRBAS, J. Some aspects of the Czechoslovak approach to problems of Functional Sentence Perspective. Mimeo. 1974.

FRIES, P.H. A personal view of Theme. In: GHADESSY, M. (Ed.). Thematic development in english texts. London: Pinter, 1995. p. 1-19.

GOTLIB, N.B. Teoria do Conto, SP: Editora Ática, 2006.

GOUTSOS, D. Modeling discourse topic: sequential relations and strategies inexpository text. NJ: Ablex, 1997.

GOUVEIA, C.; BARBARA, L. Marked or unmarked that is not the question, the question is: Where's the Theme? DIRECT Papers, n. 45, PUCSP, BR \& AELSU, University of Liverpool, UK, 2004.

GOUVEIA, C.; BARBARA, L. It is not there, but [it] is cohesive: the case of not deployd Reference in Portuguese. In: BANKS, D. (Ed.). Text and texture: systemic-functional viewpoints on the nature and structure of text. Paris: L'Harmattan, 2004(b), p. 159172.

Tema e estrutura temática em PE e PB: um estudo contrastivo das traduções portuguesa e brasileira de um original em inglês. ANAIS do $3^{\circ}$. Colóquio Português Europeu e Português Brasileiro, Universidade de Lisboa: Lisboa, FLUL, 2002, p.1-9.

HALLIDAY, M.A.K. Introduction to Functional Grammar. London: Edward Arnold, 1985; 1994.

Halliday, M.A.K. and HASAN, R. Language, context, and text: aspects of language in a socialsemiotic perspective. Oxford: Oxford University Press, 1985.

HALLIDAY, M. A. K.; MATTHIESSEN, C. M. I. M. An Introduction to Functional Grammar. London: Edward Arnold, 2004.

HICKEY, L. (Ed.).The Pragmatics of Translation. London: Multilingual Matters, 1998.

HOLLOWAY, I. Basic Concepts for Qualitative Research, Blackwell Sciente, 1997.

KUNO, S. Nihon Bunpô Kenkŷ̂. Tokyo: Taishukan, 1973.

LEONG PING, A. Talking themes: the thematic structure of talk. Discourse Studies, n. 7, v. 6, 2005, p. 701-732.

van LEUVEN-ZWART, K. Translation and original: similarities and dissimilarities I. Target. Amsterdam, n.1, v. 2, 1989, p.151-181.

Translation and original: similarities and dissimilarities II. Target. Amsterdam, n. 2, v.1, 1990, p. 69-95. 
LUCAS, N. Syntaxe Discursive du Japonais scientifique: a propos du Theme. In: Anais do II Encontro Nacional de Professores Universitários de Lingua, Literatura e Cultura Japonesa - ENPULLCJ, São Paulo, Centro de Estudos Japoneses da USP, 1991, p.77-98.

MARTIN, J.; ROSE, D. Working with discourse: meaning beyond the clause. London: Continuum, 2003.

MATHESIUS, V. O tak zvaném aktuálním clenení vetném [On the so called actual bipartition of the sentence]. SaS. Praga, n. 5, 1939, p. 171-174.

MATTHIESSEN, C.M.I.M. Theme as an enabling resource in ideational 'knowledge'construction. In: GHADESSY, M. Thematic Development in English Texts. New York: Pinter, 1995.

MUNDAY, J. Problems of applying thematic analysis to translation between Spanish and English. Cadernos de Tradução. Florianópolis, n.3,1998, p.183-214.

NAGANUMA, M. Thematic challenges in translation between Japanese and English. Interpretation Studies: Special Issue. Japan Association for Interpretatio Studies. Tokyo, Dec. 2000, p. 101-150.

NIDA, E. Language Structure and translation. Stanford: Stanford University Press CA. 1975.

NINOMIYA, S.R.L. Estruração Temática na Tradução de Textos Literários da Língua Japonesa para a Língua Portuguesa: Um Enfoque Sistêmico-Funcional. Tese de doutorado, defendida em 2012, na PUC-SP.

van OOSTEN, J. The Nature of Subjects, Topics and Agents: a cognitive Explanation. University of California: Berkeley, 1984.

PAGANO, A. Organização temática e tradução. In: ALVES, F.; MAGALHÃES, C. M.; PAGANO, A.(Org.). Competência em tradução: cognição e discurso. Belo Horizonte: editora da UFMG, 2005, p. 247-299.

PAQUILIN, V. The various facets of a message: an analysis of the thematic structure in Bridget Jones's Diary in the light of the systemic functional grammar, corpus linguistics and translation. 132 f. Dissertação (Mestrado em Letras/Inglês) -, Programa de Pós Graduação em Letras - Inglês, UFSC, Florianópolis, 2005.

RODRIGUES, R. R. A organização temática em "A hora da estrela" e "The hour of the star". 2005. 124 f. Dissertação. (Mestrado em Letras/Linguística) - Programa de Pós Graduação em Letras da UFMG. Belo Horizonte, 2005.

SHINMA, S. et al (Eds). Nihon Bungakushi (História da literatura japonesa). Tokyo: Oobunsha, 1982.

SIQUEIRA, C.P. Análise Temática em estudos de tradução: o caso dos relatórios anuais de empresas brasileiras. 2000. 123 f. Dissertação. (Mestrado em Linguística Aplicada) Programa de Pós-Graduação em Linguística Aplicada e Estudos da Linguagem, PUC-SP, São Paulo, 2000.

SLOBIN, D. Psicolinguística. São Paulo: EDUSP, 1980. 
SNELL-HORNBY, M. Linguistic transcoding or cultural transfer? A critique of translation theory in germany. In: BASSNETT, S.; LEFEVRE, A. (Eds.) Translation, History and Culture. London \& New York: Pinter Publishers, 1990, p. 79-86.

TERUYA, K. A systemic functional grammar of Japanese. London: Continuum, 2007.

THOMSON, E.A. Theme unit analysis: a systemic-functional treatment of textual meanings in Japanese. 2004. Disponível em: <http://ro.uow.edu.au/artspapers/135>. Acesso em: 10 out. 2009.

THOMPSON, G. Introducing Functional Grammar. London: Arnold, 1996. . Introducing Functional Grammar. Londres: Arnold. 2004.

VANDE KOPPLE, $\mathrm{W}$. Themes, Thematic Progressions and some Implications for understanding Discourse. London, Written Communication, n.3, v.8, 1991, p. 311-347.

VASCONCELLOS, M.L.; PAGANO, A. Explorando interfaces: Estudos da Tradução, Linguística Sistêmico-Funcional e Linguística de Corpus. In: PAGANO, A.; MAGALHÃES, C.; ALVES, F. (Org.). Competência em tradução cognição e discurso. Belo Horizonte: Editora UFMG, 2005, p.177-207.

VASCONCELLOS, M.H. Text and Translation: The Role of Theme and Information. Ilha do Desterro. Florianópolis, n.27, 1992, p.45-66.

VENTOLA, E. Thematic development and translation, in GHADESSY, M. (Ed.). Thematic development in English Texts. London \& New York: Pinter, 1995. p. 85-104.

WEIL, H. De l'ordre des mots dans les langues anciennes comparées aux langues modernes. Monograph.1844. Amsterdam: John Benjamins (Trans.), 1978. 